\title{
bases estabilizadas con cemento
}

\author{
SANDRO ROCCl, ingeniero de caminos
}

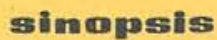

En el primero de una serie de artículos que abarcarán todos los aspectos, teóricos y prácticos, de la estabilización de suelos con cemento para afirmado de carreteras, el autor examina las características de los materiales empleados y del producto terminado, y establece los criterios de aptitud y dosificación más usuales.

\section{INTRODUCGION.}

\subsection{Definición.}

Estas bases se obtienen a partir de materiales granulares (áridos o suelos), mezclados con cantidades adecuadas de cemento y agua. y compactados después, dentro de un plazo limitado de tiempo.

\subsection{Características.}

Estas bases se obtienen a partir de materiales ón al material, proporeionándole una rigidez sensible, por lo que la base funciona ya como una losa, repartiendo las cargas del tráfico sobre una superficie mayor como si se tratara de una base granular; además, el material resulta prácticamente inalterable por los agentes ecológicos (humedad, temperatura). Al mismo tiempo, dicha rigidez no es demasiado elevada, permitiendo que la base se adapte a deformaciones lentas de las capas subyacentes, sin que se produzcan agrietamientos excesivos, como en el caso de un firme rígido. Se trata, por lo tanto, de un material distinto, tanto de las bases granulares como de los firmes rígidos $\mathrm{y}$, en cierto modo, intermedio entre los dos.

\subsection{Materiales.}

El material natural, que es el que entra en la mezela en mayor cantidad (alrededor del 90 por 100 en peso), puede ser seleccionado o no. En el primer caso se le denomina «árido», debiendo cumplir unas limitaciones en cuanto a granulometría y plasticidad: al resultado de su mezcla con cemento y agua se le denomina «hormigón magro». A partir de los materiales que se denominan «suelos», en los que las limitaciones son bastante menos exigentes, se obtienen los «suelocementos».

El componente estabilizador, o sea, el cemento, se incorpora de forma íntima al material natural por medio de la operacićn que se denomina «mezcla». Su proporción (dosificación) debe ser suficiente para conferir a la base ciertas cualidades mínimas de insusceptibilidad, resistencia mecánica y durabilidad. 


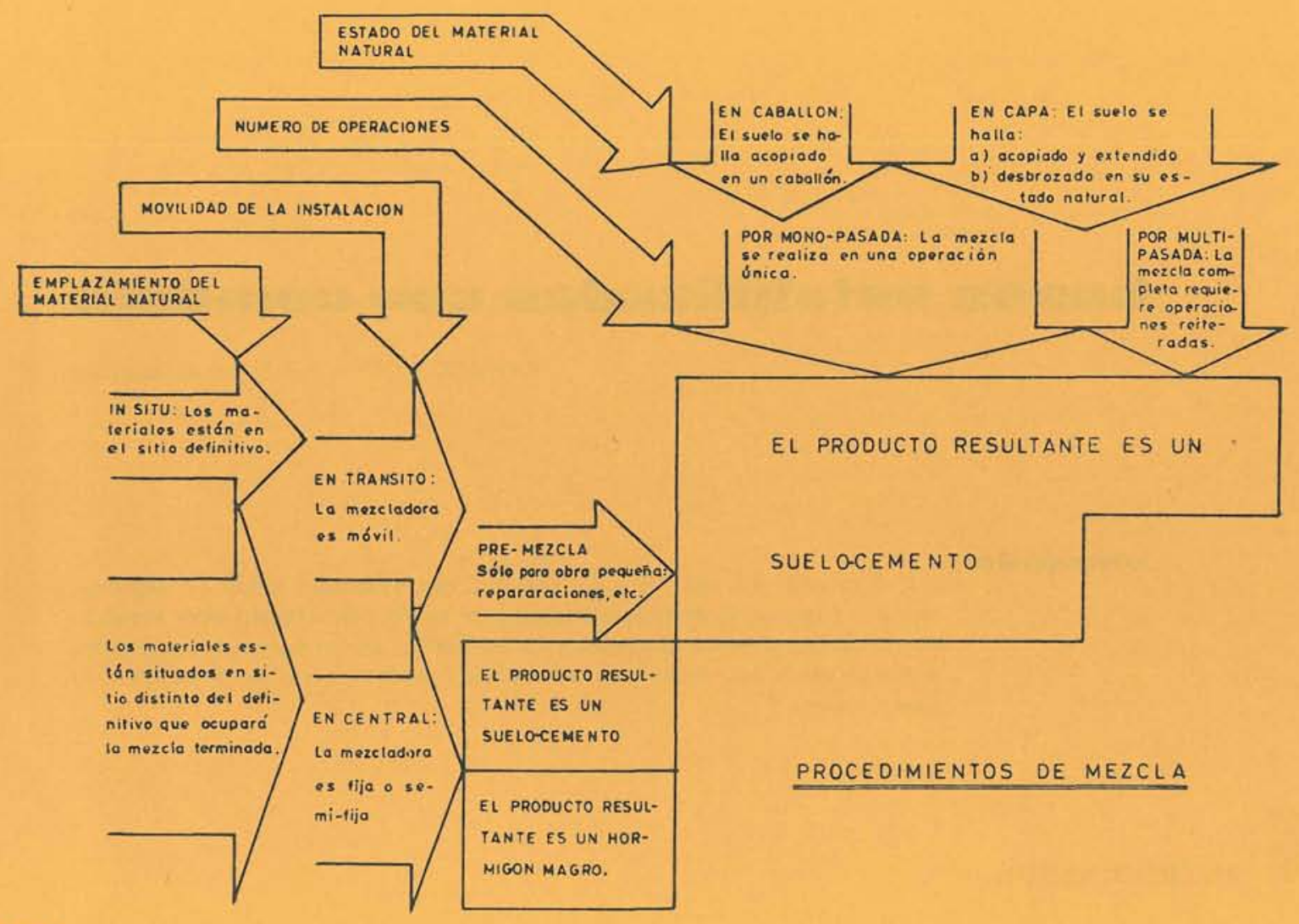

Fig. 1

El agua se añade en la proporción óptima para obtener la máxima densidad al compactar; además, parte de ella sirve luego para hidratación del cemento.

\subsection{Métodos de mezcla.}

La mezcla de los componentes puede realizarse por varios procedimientos, descritos esquemáticamente y clasificados con arreglo al emplazamiento y estado del material natural, movilidad de la instalación y número de operaciones necesarias, en la figura 1.

\subsection{Limitaciones.}

El método por el cual se efectúa la mezcla es determinante de muchas características técnicas y constructivas de las bases estabilizadas con cemento.

1.5.1. Limitaciones geométricas.-Así, por ejemplo, el espesor de dicha base que se construya de. una vez estará determinado, en el caso de mezcla en central, por el alcance eficaz del equipo de compactación que se esté utilizando (normalmente, de 25 a $30 \mathrm{~cm}$ ); pero en el caso de mezcla en tránsito, el espesor estará limitado por el alcance de las paletas de la máquina mezcladora, que generalmente es menor que el anterior $(15$ a $20 \mathrm{~cm}$ ); en el caso de premezcla, actúa la segunda limitación al mezclar, y la primera, al extender y compactar. También el ancho total estabilizado, en el caso de mezcladoras por monopasada, no es arbitrario, sino que, por razones de facilidad de construcción, se ajusta a un múltiplo del ancho eficaz de la máquina: el cual a veces es regulable. Se recomienda construir la base con unas creces mínimas de $30 \mathrm{~cm}$ a cada lado de la calzada, para la contención lateral del firme. 
1.5.2. Limitaciones de tiempo.-Como en todas las obras en las que interviene el cemento, al entrar éste en contacto con el agua se inicia un proceso irreversible de fraguado y endurecimiento, que hace que el tiempo de que se dispone para transportar, extender y/o compactar y refinar la base sea limitado, so pena de mermar las características resistentes de la misma. La presencia de este plazo limitado obliga a euidar de la programación de las diversas operaciones de que consta la construcción; y a adoptar ciertas medidas especiales, según el método de mezcla; por ejemplo: prefijar la longitud del tajo diario (multipasadas); disponer juntas (monopasadas o central). También existe un plazo mínimo de curado, antes de que pueda someterse la base a la acción del tráfico (incluso el de obra): este plazo depende, fundamentalmente, de las características de dicho tráfico.

1.5.3. Limitaciones climatológicas.-Se incluyen en este apartado las limitaciones a la construcción causadas por la lluvia o el frío.

Las limitaciones debidas a la lluvia dependen, a que en cualquier otra obra en que intervenga el cemento, cuyo fraguado se detiene a $0^{\circ} \mathrm{C}$; sumándose al nocivo efecto anterior la expansión producida por la congelación del agua contenida en la base, cuando el cemento no ha endurecido aún lo suficiente. Por lo tanto, siempre que haya motivo razonado para suponer que helará dentro de las cuarenta y ocho horas siguientes a la construcción de la base, deberá suspenderse ésta; la base se protegerá contra la helada durante siete días con paja, sacos, tierra, etc.

Las limitaciones debidas a la lluvia dependen asimismo, del procedimiento constructivo empleado. Las operaciones podrán proseguirse a pesar de la lluvia, siempre y cuando ésta no haga que la humedad en el momento de compactar rebase la óptima especificada. Además, algunos métodos de mezcla «in situ» requieren una distribución muy anticipada del cemento sobre el suclo acopiado o extendido: operación que no es posible con lluvia, porque el cemento se hidrataría antes de su mezcla con el suelo.

\section{CONDIGIONES FACULTATIVAS.}

\subsection{Concepto.}

Las condiciones facultativas, a las que hace mención un Pliego de Condiciones, se refieren a la forma y al material de la base estabilizada, de los que se trata en este epígrafe; y a los materiales componentes, y proceso constructivo de la misma, de los que se trata más ampliamente en epígrafes sucesivos.

\subsection{El material de la base.}

En el material de la base terminada pueden distinguirse dos tipos de características: las intrínsecas, o propias del material, sea cual fuere su estado; y las accidentales, que dependen de dicho estado.

2.2.1. Estado del material de la base.-El «estado» del material lo define su compactación. Esta ha de ser tal, que la base en todo punto presente una densidad no inferior a la máxima obtenida en un Ensayo Normal de Compactación (E. N. C.), realizado con una presión equivalente (energía por unidad de volumen) correspondiente al equipo de compactación que se va a emplear en obra, y no inferior a $6,05 \mathrm{~kg} / \mathrm{cm}^{2}$. También es fundamental que dicha densidad se alcance en presencia de una humedad lo más cercana posible a la óptima (humedad correspondiente a la máxima densidad en el E. N. C.).

2.2.2. Características del material de la base.-En cuanto a las características de material c.e la base estabilizada, las condiciones facultativas hacen referencia a una intrínseca: la insusceptibilidad al agua; y a tres accidentales, anejas al estado de máxima compactación: la resistencia mecánica. la deformabilidad y la durabilidad.

Por insusceptibilidad al agua se entiende la propiedad de mantener, dentro de ciertos límites, Jas características geotécnicas del material (plasticidad, cambios volumétricos, absorción) relacionadas con el comportamiento del mismo en presencia del agua. La resistencia mecánica es el conjunto de 
propiedades reológicas que hacen a la base compactada apta para soportar cargas concentradas en su parte superior (producidas por el tráfico), repartiendo su efecto sobre superficies progresivamente mayores. La durabilidad es la facultad de conservar, dentro de ciertos límites, la antedicha resistencia mecánica, a pesar del efecto de los agentes ecológicos (humedad, temperatura). La deformabilidad es la propiedad que tiene la base de mudar su forma al aplicársele cargas exteriores, o al producirse asiento en las capas subyacentes, sin que aparezca una fisuración excesiva; es inversamente proporcional a la resistencia mecánica, por lo que generalmente, en vez de exigir una deformabilidad mínima, se limita la resistencia a un máximo.

Las características enumeradas en el párrafo anterior son susceptibles de medirse a través de ensayos representativos, salvo la deformabilidad, para la cual no se ha normalizado aún ningún ensayo. Los resultados de estos ensayos deben cumplir ciertas limitaciones, distintas según se trate de hormigones magros o de suelocementos, y aun, dentro de estos últimos, según las características del suelo del que se ha partido.

\subsection{Condiciones para los hormigones magros.}

En cuanto a los hormigones magros, las únicas condiciones que se suelen exigir se refieren a la resistencia mecánica, puesto que las limitaciones que se imponen al árido del que se parte hacen que éste sea por sí solo insusceptible al agua; y que normalmente, una vez adquirida la resistencia mecánica necesaria, presente durabilidad frente a las bajas temperaturas, a no ser que el árido sea heladizo. No se suele exigir tampoco condición de deformabilidad mínima, aunque un criterio lógico sería limitar la resistencia mecánica del hormigón magro al valor de la mínima exigida para el hormigón de un firme rígido (que va provisto de juntas especiales para compensar su falta de deformabilidad; lo cual no es el caso con un hormigón magro); en la práctica, la deformabilidad empieza a ser problemática a partir de una resistencia a compresión simple superior a $150 \mathrm{~kg} / \mathrm{cm}^{2}$ a los veintiocho días.

2.3.1. Resistencia a compresión.-La resistencia del hormigón magro a compresión simple, medida sobre probetas cúbicas de $15 \mathrm{~cm}$ de lado, compactadas al máximo en tres tongadas, y curadas en ambiente normalizado como si se tratara de hormigón normal, deberá ser, como mínimo, $100 \mathrm{~kg} / \mathrm{cm}^{2}$ a los veintiocho días.

2.3.2. Heladicidad.-En los casos en que se sospeche que el árido es heladizo, puede exigirse la siguiente comprobación: se moldean dos series de probetas, curándolas en ambiente normalizado durante siete días, al cabo de los cuales una serie se somete a 14 ciclos de congelación en su cara superior, con la inferior sumergida, dieciséis horas a $-5^{\circ} \mathrm{C}$ y ocho horas a $25^{\circ} \mathrm{C}$, mientras que la segunda serie se sumerge en agua los catorce días; al cabo de dicho tiempo se determina su resistencia a compresión simple: la de las primeras no debe ser inferior al 75 por 100 de las segundas. En caso contrario, puede exigirse una compactación más enérgica, o bien rechazar el árido.

\subsection{Condiciones para los suelocementos.}

En cuanto a los suelocementos, las características del material en estado compactado se ordenan, para una misma dosificación de cemento, de forma que, si se cumplen las condiciones facultativas referentes a la durabilidad, automáticamente se cumplen las demás, en la mayoría de los casos; y si se cumplen las referentes a resistencia mecánica, automáticamente también se cumple la referente a insusceptibilidad al agua, en la mayoría de los casos (la deformabilidad es un criterio aparte, cuya exigencia, como se ha dicho más arriba, se concreta en limitar superiormente la resistencia mecánica, que es inversamente proporcional a ella). Esta ordenación de las características permite un gran ahorro de trabajo al controlar el suelocemento, puesto que una vez determinada previamente (e incluso «a priori») cuál es la característica «crítica», cumplidos cuyos requisitos se cumplen también los de las demás, basta con controlar dicha característica sin preocuparse de las demás, más que para comprobar, de vez en cuando, que el material no ha variado lo suficiente como para hacer que la característica elegida deje de ser crítica.

2.4.1. Insusceptibilidad al agua._Las exigencias de insusceptibilidad al agua se definen por tres ensayos:

2.4.1.1. Plasticidad.-El índice de plasticidad de probetas de suelocemento compactadas en condiciones óptimas, curadas durante siete días en ambiente normalizado y disgregadas a continuación, 
será igual o inferior a 10. Si se tuviera duda sobre la permanencia del efecto del cemento, podrán someterse las probetas a 30 ciclos de congelación antes de disgregarlas; en este caso, el índice de plasticidad no deberá rebasar 12 .

2.4.1.2. Retracción y entumecimiento.-El coeficiente volumétrico de retracción del suelocemento compactado en condiciones óptimas no deberá ser superior a la mitad del correspondiente al suelo solo.

El coeficiente volumétrico de entumecimiento del suelocemento compactado en condiciones óptimas no deberá rebasar el 2 por 100 .

2.4.1.3. Absorción de agua por capilaridad.—La absorción de agua en veinticuatro horas de probetas de suelocemento, compactadas con el 85 por 100 de la humedad óptima, y curadas en ambiente normalizado hasta que sólo contengan el 55 por 100 de dicha humedad, no deberá rebasar el 30 por 100 de la misma.

2.4.2. Resistencia mecánica.-Las exigencias de resistencia mecánica se definen por dos ensayos:

2.4.2.1. Resistencia a compresión simple.-Esta resistencia, medida a los siete días sobre probetas cilíndricas de doble altura que diámetro, compactadas en condiciones óptimas y curadas a temperatura y humedad constante, no deberá ser inferior a $17,5 \mathrm{~kg} / \mathrm{cm}^{2}$.

2.4.2.2. Resistencia a la penetración.-La relación de penetración por cilindro (CPR), medida con la técnica C. B. R. sobre probetas compactadas en condiciones óptimas y curadas durante siete días a humedad y temperatura constantes, no deberá ser inferior a 120.

2.4.3. Deformabilidad.-Las exigencias de deformabilidad se definen por los mismos ensayos que la resistencia mecánica, a los que se fijan los valores máximos, respectivamente, de $25 \mathrm{~kg} / \mathrm{cm}^{2}$ y 350 .

2.4.4. Durabilidad.-Las exigencias de durabilidad se definen por unos ensayos de abrasión. Estos ensayos son, sin embargo, muy largos y requieren tiempo costoso; por lo que se suelen sustituir por ensayos acelerados, basados en la resistencia a compresión simple.

2.4.4.1. Pérdidas por abrasión.-Estas pérdidas, medidas en probetas compactadas en condiciones óptimas y curadas en ambiente normalizado durante siete días, sometidas a 12 ciclos de inmersióndesecación-abrasión, o a 12 de congelación-deshielo-abrasión, no deberán rebasar el 14 por 100 para suelos arenosos no plásticos; el 10 por 100, para suelos arenosos plásticos y suelos limoarcillosos poco plásticos, y el 7 por 100, para suelos limoarcillosos plásticos.

2.4.4.2. Ensayos acelerados.-Son de dos modalidades, según el tipo de suelo:

a) Suelos arenosos: la resistencia mínima a exigir de probetas de 4 " $(10 \mathrm{~cm})$ de diámetro y 4,59" $(11,6 \mathrm{~cm})$ de altura, compactadas en condiciones óptimas, curadas durante siete días en ambiente normalizado, y sumergidas en agua durante cuatro horas antes de romperlas, está relacionada con la granulometría del suelo, según muestra la figura 2.

b) Suelos limoarcillosos: la resistencia de probetas de doble altura que diámetro, compactadas en condiciones normales y curadas durante siete días a humedad y temperatura constante, y sometidas a 14 ciclos de congelación o sumergidas durante siete días, no deberá ser inferior al 75 por 100 de la resistencia de probetas análogas, que, en vez de someterse a esos ciclos, se hubieran conservado en ambiente normalizado.

\subsection{Condiciones de forma de la base.}

Las condiciones facultativas que se refieren a la forma de la base estabilizada consideran dos aspectos de la misma: sus dimensiones y su regularidad superficial.

En cuanto a las dimensiones geométricas, vienen fijadas en los planos, y únicamente cabe hacer tolerancias en cuanto al espesor; más adelante, en el epígrafe dedicado a «Control geométrico», se trata de ellas.

La regularidad superficial de una capa de base es muy importante, puesto que sólo la capa de rodadura la separa del tráfico; sin embargo, el plazo limitado de tiempo de que se dispone para terminar el refino hace que en la práctica sea difícil alcanzar la misma regularidad que en el caso de una 


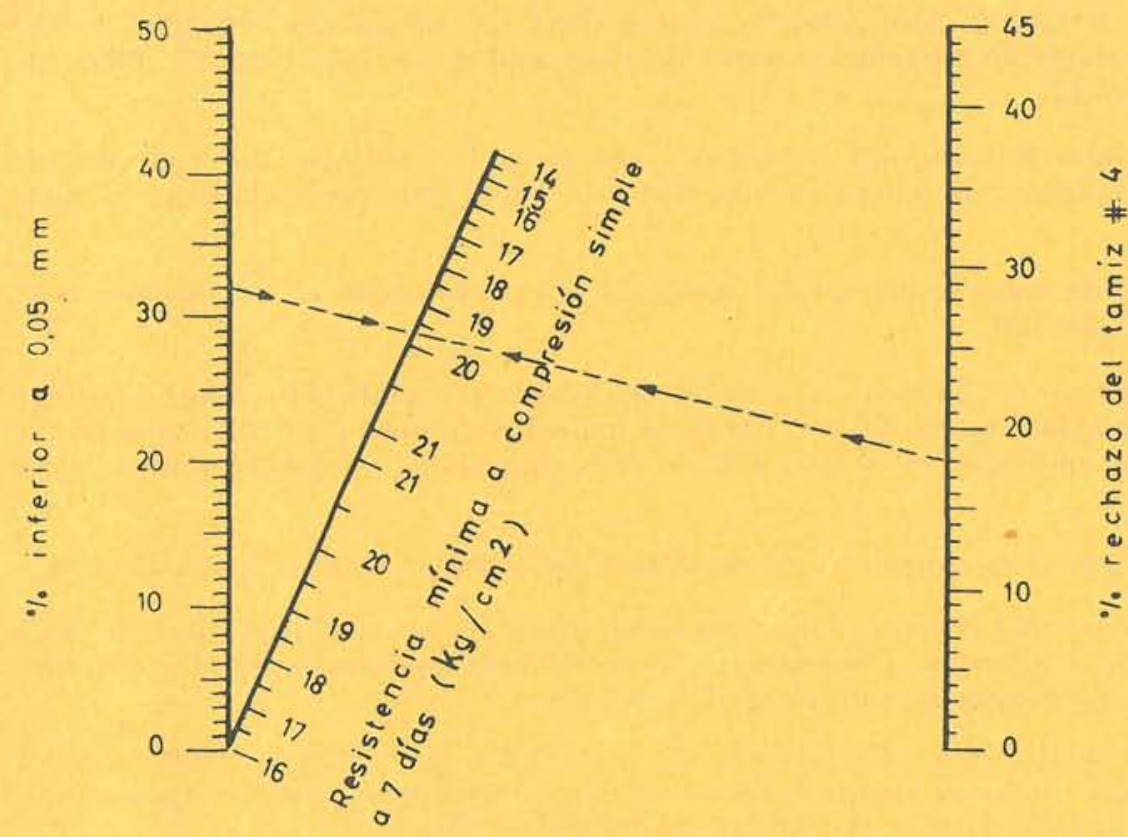

Fig. 2,-Criterio acelerado de durabilidad para suelos arenosos.

base granular, en la que el tiempo de que se dispone es ilimitado. Las tolerancias son de $10 \mathrm{~mm}$ en $3 \mathrm{~m}$ para la base terminada; entre 10 y $25 \mathrm{~mm}$ se debe estudiar la ejecución de una capa de regularización antes de la construcción del pavimento propiamente dicho. Por encima de $25 \mathrm{~mm}$ se rechazará la base.

\section{OBTENCION DE MATERIALES.}

\subsection{Materiales naturales.}

3.1.1. Criterios de exclusión.-Las bases estabilizadas con cemento pueden obtenerse a partir de la casi totalidad de los materiales naturales, siempre que no presenten incompatibilidades químicas con el cemento (materia orgánica en proporción superior al 2 por 100 en peso, o sulfatos en proporción superior al 1 por 100$)$.

Las características identificatorias (granulometría y límites de Atterberg) que corresponden a los materiales naturales con los que pueden construirse bases estabilizadas, están resumidos en las figuras 3 y 4 .

3.1.2. Criterios de clasificación.-Los materiales más seleccionados (áridos), cuya granulometría esté dentro del huso de la figura 5 , dan origen a hormigones magros. También pueden dar origen a hormigones magros materiales cuya granulometría se salga parcialmente de dicho huso, siempre que el coeficiente de curvatura de la granulometría $\left(d^{2}{ }_{30} / d_{60} \cdot d_{10}\right)$ sea inferior a 0,6 . En cuanto a los límites de Atterberg, deberán estar comprendidos dentro de la zona señalada en la figura 6.

Todos los materiales que no estén comprendidos en los anteriores serán considerados como suelos. obteniéndose de ellos suelocementos. En la figura 7 se distinguen los husos correspondientes a suelos arenosos y suelos limoarcillosos; y en la figura 8, las zonas correspondientes a suelos poco plásticos y a suelos plásticos.

3.1.3. Criterios de aptitud.-La mayor o menor aptitud del material para ser estabilizado con cemento está representada por la dosificación de éste que necesita para cumplir las condiciones facultativas. Esta dosificación se fija mediante un estudio que, por lo general, es largo de realizar. Por ello, cuando se realizan prospecciones de yacimientos, y se trata de discernir «a priori» si un material presenta una reacción normal con el cemento, o cuál de varios materiales es el más adecuado, se recurre a unos criterios de aptitud simplificados, que permiten ahorrar mucho tiempo y esfuerzo, y se aplican, fácil y rápidamente, a gran número de muestras. Naturalmente, los criterios de aptitud no son eliminatorios, sino orientativos: el estudio de dosificación es quien tiene la última palabra. 


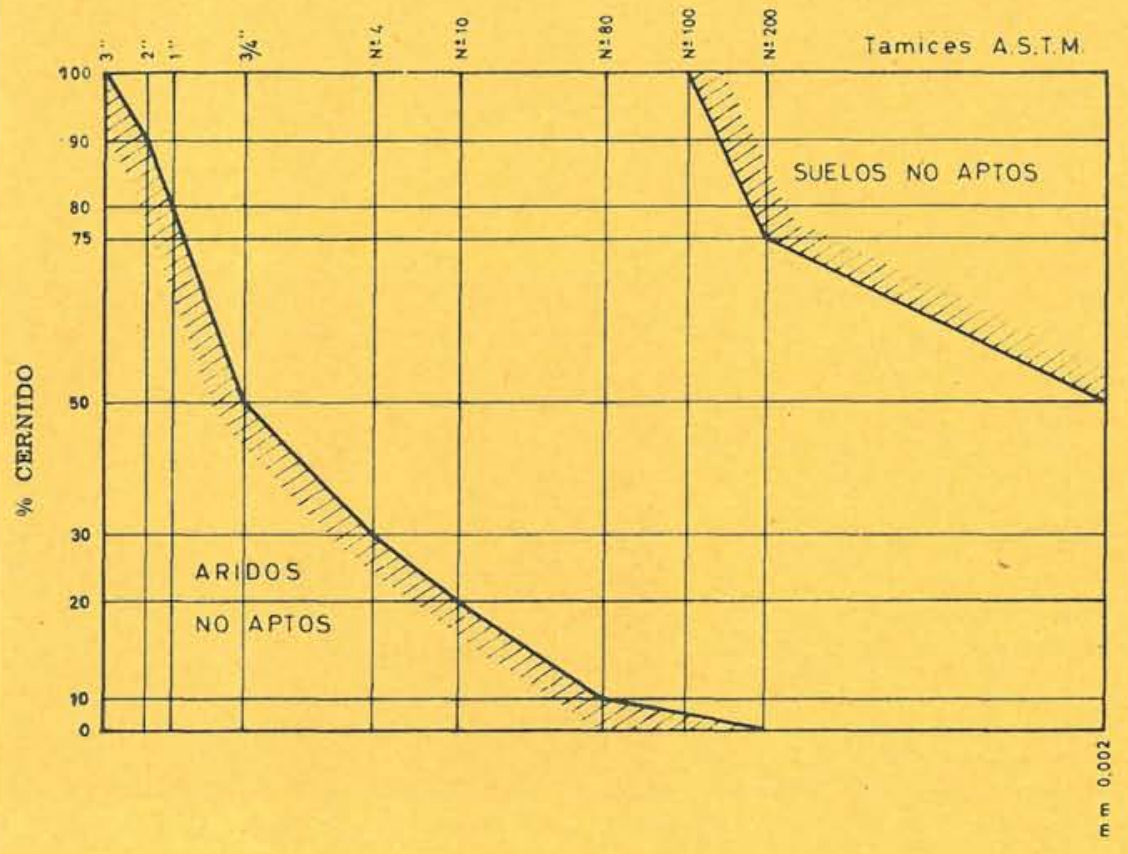
Figs. 3 y 4.-Características identificatorias
de los materiales naturales que se pueden
estabilizar.

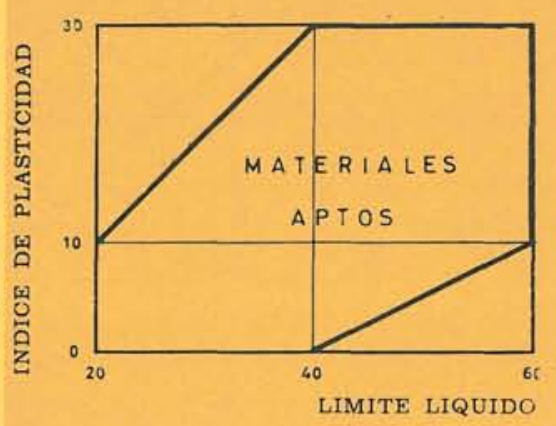

Estos criterios simplificados de aptitud son de dos tipos: los que se aplican a las características identificatorias del material y los que recurren a un ensayo empírico. Los criterios de aptitud descritos a continuación se aplican sobre todo a suelos, puesto que los correspondientes a los áridos (materiales seleccionados) son precisamente los criterios de clasificación.
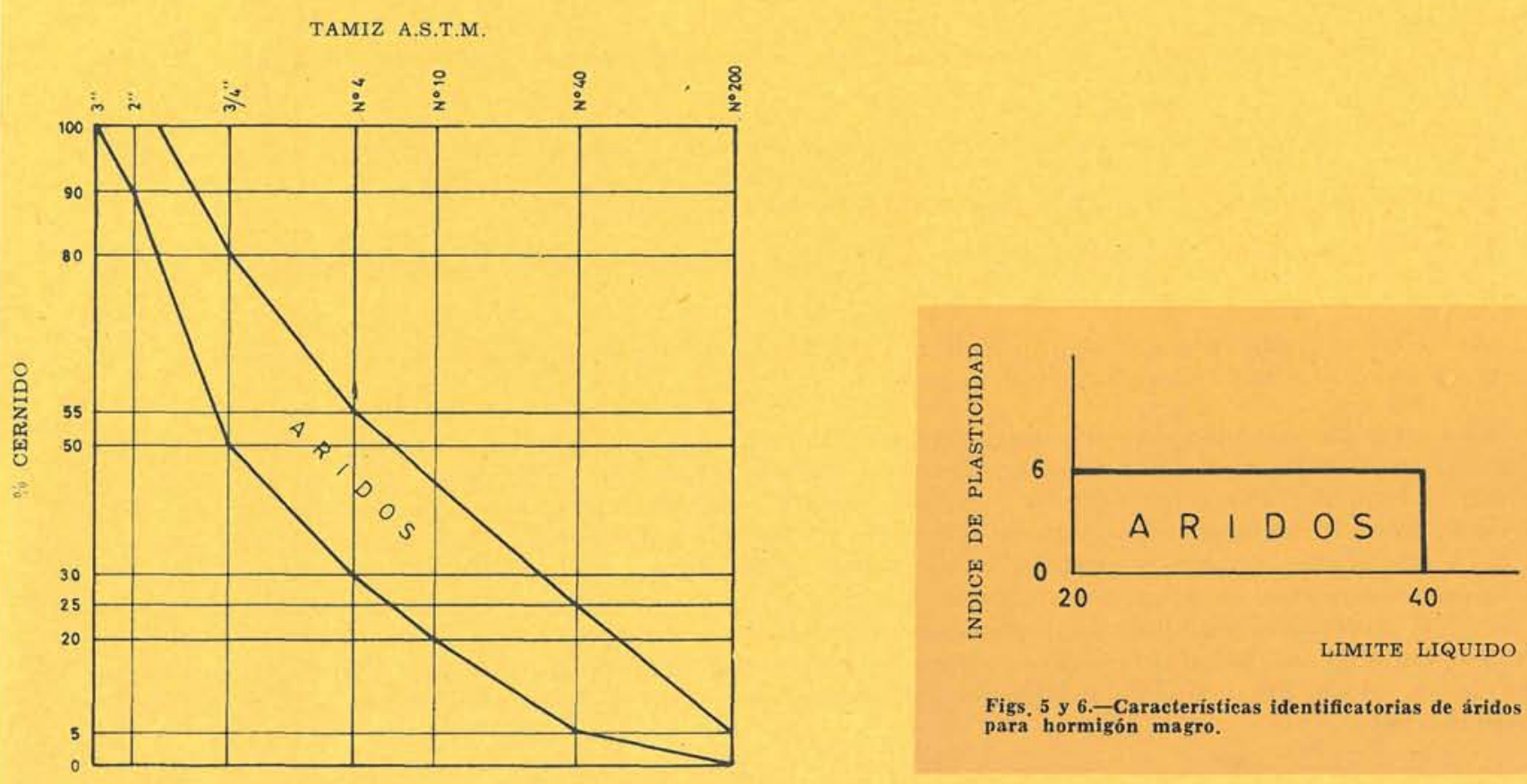

Figs, 5 y 6.-Caracteristicas identificatorias de áridos para hormigón magro. 

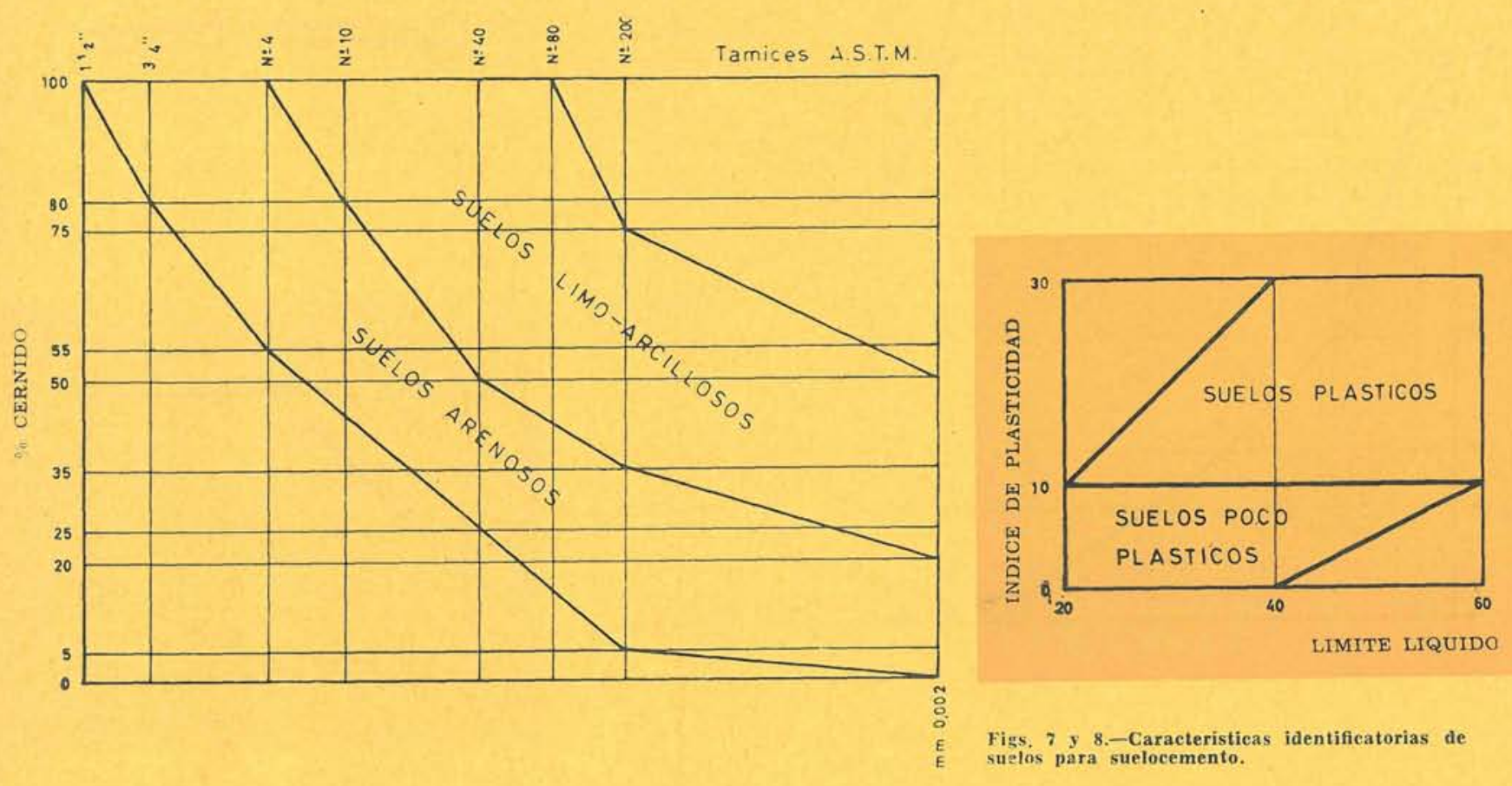

3.1.3.1. Características identificatorias.-En cuanto a los criterios de aptitud que se aplican a las características identificatorias, se reducen a los siguientes:

- Un suelo arenoso es más apto que uno limoarcilloso.

- Un suelo poco plástico es más apto que uno plástico.

- Los suelos cuya granulometría está comprendida parcialmente en el huso (fig. 5) de los áridos, son menos aptos que los suelos arenosos, pero más que los limoarcillosos.

- Los suelos cuyo coeficiente de uniformidad $\left(d_{60} / d_{10}\right)$ sea bajo, son menos aptos que los que lo tienen alto.

3.1.3.2. Ensayos empíricos.-Los ensayos empíricos que dan origen a criterios de aptitud son los siguientes:

Equivalente de arena: Un equivalente de arena inferior a 30 o superior a 50 indica un suelo poco apto.

$p H$ del suelo: Un suelo limoarcilloso con $\mathrm{pH}$ inferior a 7 es poco apto.

Factor de absorción de calcio: Un suelo arenoso con un factor de absorción de calcio superior a 11 es poco apto.

$p H$ de un suelocemento tipo: $\mathrm{Si}$ el $\mathrm{pH}$ de un suelocemento tipo, medido a los quince minutos de amasado, es inferior a 12,2 , el suelo es poco apto.

3.1.4. Origen del material.-Es absolutamente necesario que el material natural que se utilice para mezclar sea aquel mismo para el que se ha llevado a cabo el estudio de dosificación. Esto, que en el caso de áridos es bastante fácil, puesto que se mezcla en central y además cualquier variación de naturaleza en el árido se acusa fuertemente en su aspecto, no lo es tanto en el caso de suelos, frecuentemente mezclados «in situ», y en los que variaciones importantes de su naturaleza (p. ej., en contenido de materia orgánica) no se acusan demasiado en su aspecto exterior. Además, al hacer prospecciones, interesa que los criterios de aptitud (y eventuales estudios de dosificación) representen a la mayor cantidad del material posible. Se ve, por tanto, la necesidad de establecer, para los suelos, una unidad de definición, análoga al «yacimiento» de los áridos. Esta unidad de definición está basada en unos conceptos edafológicos, que se exponen a continuación: 
El suelo se forma a partir de un material primario (llamado a veces «roca madre» u «horizonte $\mathrm{C} »)$, generalmente una roca, aunque puede ser otro suelo (que entonces se llama relicto), por descomposición físico-química causada por la acción conjunta de los agentes ecológicos (humedad, temperatura, vegetación). Bajo esta acción conjunta, modificada localmente por circunstancias topográficas (relieve, escorrentía), se diferencian en el material primario unos estratos u «horizontes» de diversa composición, textura y color. El proceso de solificación es permanente, y afecta a la capa superficial del terreno. En el conjunto de horizontes, denominado «perfil edafológico», se distinguen: la capa superficial (horizonte A), frecuentemente rica en materia orgánica de origen vegetal, y de la que las aguas pluviales tienden a lavar las sales solubles y partículas finas hacia horizontes más profundos (zona de eluviación); la capa intermedia (horizonte B), a la que afluyen las sales solubles (carbonato cálcico, principalmente) y las partículas finas procedentes del horizonte A; es la zona de iluviación. Más abajo, el horizonte $\mathrm{C}$, o material original, que puede llegar a desaparecer. Existen además subdivisiones en estos horizontes, que no interesan aquí.

El perfil del suelo puede inspeccionarse fácilmente en desmontes o en calicatas. Se llama «serie edafológica» a un conjunto de suelos procedentes de un mismo material original, y que a través de parecidas circunstancias ecológicas presentan un perfil idéntico en cuanto a su orden y naturaleza, con excepción de la textura granulométrica del horizonte superior. Con arreglo a esta última se definen los «tipos edafológicos» dentro de la «serie».

Es lógico pensar, y la experiencia lo ha confirmado, que los suelos procedentes de análogos horizontes de igual serie edafológica (para los horizontes inferiores) o de igual tipo edafológico (para el horizonte superior) presentan las mismas propiedades y, concretamente, la misma aptitud para estabilizarse con cemento. Basándose en todas estas consideraciones, se obtienen las siguientes conclusiones:

- No deben mezclarse entre sí, a no ser que se haga en acopios perfectamente controlados, suelos procedentes de horizontes o tipo diferentes, con intención de estabilizarlos.

- Los estudios de dosificación siempre deben efectuarse sobre muestras representativas del horizonte a que va a pertenecer el material (si es suelo) o del yacimiento (si es árido).

- Una vez aplicados los criterios de aptitud a un tipo de suelo, en sus diversos horizontes, valen para los suelos de igual tipo, aunque estén en distinto lugar. Especialmente útil es, para ello, utilizar los mapas edafológicos empleados en Agricultura, en los que los suelos están diferenciados por tipos.

- Los suelos procedentes del horizonte A son peligrosos, porque pueden contener materia orgánica.

\subsection{E1 cemento.}

3.2.1. Tipo de cemento.-No existen preferencias en cuanto al tipo de cemento utilizable para bases estabilizadas, siempre que cumpla las condiciones definidas en el vigente Pliego General de Condiciones para la Recepción de Conglomerantes Hidráulicos (OO. MM. 31-12-1959 y 26-7-1960); si bien se deberán utilizar cementos tipo PAS (resistentes a la acción de los sulfatos) cuando la proporción de sulfatos en el suelo exceda del 0,5 por 100 en peso.

El estudio de dosificación deberá llevarse a cabo con el mismo tipo y marca de cemento que luego se vaya a emplear en obra.

3.2.2. Almacenamiento del cemento.-Para evitar que el cemento ensacado pierda sus propiedades por efecto de la humedad, se cuidará que el almacenamiento del mismo sea en lugar ventilado y al abrigo de la intemperie, apilando los sacos sobre tarimas separadas de las paredes del almacén, dejando corredores entre las pilas de sacos y tarimas secundarias cada cuatro capas de sacos para permitir el paso del aire. Si el cemento se suministra a granel, deberá exigirse que los envases metálicos y sus conexiones estén debidamente limpios y sean suficientemente estancos.

3.2.3. Recepción.-Con el fin de comprobar que el cemento cumple las prescripciones del Pliego General, se realizarán los ensayos indicados en el mismo. Además, cuando el cemento haya de per- 
manecer almacenado durante tres o más semanas en condiciones atmosféricas normales, se repetirán los ensayos de recepción por este orden:

Residuo sobre tamiz de 4.900 mallas.

Pérdida al fuego.

Ensayos restantes.

Basta con que se cumpla el primero de estos requisitos o, en su defecto, el segundo, para que el cemento sea declarado apto.

\subsection{El agua.}

Al igual que con Ios materiales naturales, la gama de aguas aptas para la construcción de bases estabilizadas es muy amplia, con inclusión del agua de mar, y la natural exclusión de las aguas selenitosas y las que contienen aceites, grasas u otra materia orgánica. Si surgiera duda sobre su aptitud, especialmente en el caso del agua de mar, se podrá repetir el estudio de dosificación con el agua sospechosa; modificando la dosificación en consecuencia, si es preciso. El agua potable no medicinal será declarada apta sin más requisitos.

\subsection{Otros materiales.}

Bajo este epígrafe se agrupa a las inclusiones y a las adiciones.

3.4.1. Inclusiones.-Se llama inclusiones a las sustancias contenidas en el material natural y que no son de la misma naturaleza que éste: como ejemplo clásico se tienen los ligantes bituminosos procedentes de antiguos firmes.

La presencia de inclusiones, que en ningún caso deberán superar al 25 por 100 del total considerado como material natural, no perjudicará a las condiciones facultativas; realizándose, si se estimara conveniente, los oportunos ensayos.

3.4.2. Adiciones.-Bajo esta denominación se designa a ciertas sustancias cuya inclusión en la base estabilizada con cemento es deliberada, obedeciendo al propósito de utilizar un material natural que, de lo contrario, no sería apto, o de rebajar la dosificación de cemento, o de trabajar en condiciones especiales que, de otro modo, no se tolerarían.

Las adiciones deben ser homologadas mediante ensayos que demuestren que, en la proporción en que se van a añadir, y con las dosificaciones de cemento y agua que se vayan a emplear (eventualmente modificadas), cumplen su misión específica, no alterando las condiciones facultativas; los valores tope fijados en el epígrafe 2.2 para dichas condiciones pueden rebajarse en un 20 por 100 de su valor original.

Las adiciones pueden incorporarse al material natural, al cemento o al agua.

3.4.2.1. Adiciones al material natural.-Frecuentemente se trata de otro material natural de me-: jores características. No se limita la proporción, pero hay que comprobar que el conjunto presenta homogeneidad, y someterlo de nuevo al estudio de dosificación.

3.4.2.2. Adiciones al cemento-Obligatoriamente las adiciones serán materiales granulares secos y no higroscópicos, en proporción no superior a la de cemento. La incorporación a éste deberá realizarse con preferencia en fábrica; y de hacerse en obra, el procedimiento deberá ser aprobado y comprobada la homogeneidad del resultado.

3.4.2.3. Adiciones al agua.-Las adiciones serán productos solubles o emulsionables, dosificándose en peso de adición por volumen de agua, y disponiéndose los medios oportunos para que la solución o emulsión sea completa antes de emplearse en obra. 


\section{ESTUDIO DE DOSIFICACION.}

\subsection{Objeto del estudio de dosificación.}

Una vez definidos los materiales de forma inequívoca, se realiza un estudio sobre muestras represenlativas de ellos, con objeto de determinar tres datos para la construcción:

- El estado mínimo de compactación en que debe hallarse la base construida para que cumpla las condiciones facultativas accidentales de resistencia y durabilidad. Este estado se define por medio de una densidad, cuya medida le da un peso específico conjunto (peso de materiales sólidos por unidad de volumen, incluyendo todos los huecos y estando éstos totalmente rellenos de aire), que se expresa en $\mathrm{kg} / \mathrm{dm}^{3}$.

- La humedad óptima de compactación, por encima de la cual no es posible alcanzar el estado mínimo de compactación sin alterar las condiciones facultativas accidentales (resistencia y durabilidad) de la base. Esta humedad se define como un porcentaje ponderal de agua respecto de sólidos y también es función de la energía de compactación.

- La dosificación mínima de cemento para que la base cumpla las condiciones facultativas intrínsecas (insusceptibilidad al agua), y además en el estado mínimo de compactación cumpla las condiciones facultativas accidentales (resistencia y durabilidad). Esta dosificación, que se expresa en porcentaje ponderal de cemento respecto del material natural seco, es a la vez resultado y dato inicial del estudio, puesto que influye en el resultado del ensayo de compactación; por lo tanto, es necesario estimarla al principio del estudio de dosificación, en función de las características identificatorias del material natural.

\subsection{Compactación.}

4.2.1. Estructura interna de la base.-La resistencia de la base depende de su estructura interna, que el cemento se encarga de mantener (durabilidad). Dicha estructura interna es la disposición de unas partículas con respecto a otras, en posiciones más o menos estabies frente a los agentes exteriores que tiendan a desplazarlas.

4.2.2. Relaciones voluméiricas.-En un volumen unitario de base, se pueden distinguir: el volumen ocupado por los sólidos (material natural y cemento) dispuestos según una estructura interna determinada, y el volumen de huecos; éstos pueden estar rellenos de agua o de aire, llamándose «grado de saturación» a la relación entre el volumen ocupado por el agua y el volumen total de huecos.

Las propiedades resistentes de la estructura interna de la base se aumentan generalmente cuando el «índice de huecos», $e$ (relación entre el volumen de huecos y el volumen de sólidos), disminuye: esto es evidente, puesto que, al disminuir los huecos, los sólidos se disponen de forma más apretada, multiplicándose los contactos entre partícuias. Si la disminución de huecos totales se realiza a costa de los huecos ocupados por el aire, el proceso se llama «compactación» y es relativamente rápido; si son los huecos rellenos de agua los que se reducen (expulsándose, por lo tanto, el agua), el proceso se llama «consolidación» y es lento; además, para ello hace faita que ya no queden huecos rellenos de aire, o sea, que la saturación sea total. Es importante observar que la saturación aumenta a medida que la compactación progresa, puesto que se elimina aire sin eliminar agua. En la práctica, por medio de la compactación no se llega a eliminar totalmente el aire, quedando un volumen de huecos de aire absorbido a las partículas sólidas, que puede llegar a ser el 5 por 100 del total de huecos: esta situación se llama «pseudosaturación».

Aunque la medición del volumen total, $\mathrm{V}_{\text {, }}$, de la base resulta bastante fácil, no se puede medir directamente el volumen real ocupado por los sólidos de la misma, $V_{s}$ (y, por tanto, el volumen de huecos, $V_{h}=V_{t}-V_{s}$ ); acudiendo entonces a determinar el peso de sólidos, $P_{s}$ (lo cual es fácil, puesto que el aire no pesa y el agua se puede eliminar por desecación), y su peso específico neto, $\gamma_{s n}$ (el de los sólidos secos, con exclusión de los huecos comunicados con el exterior, el cual es constante si no varía la naturaleza de los sólidos). 


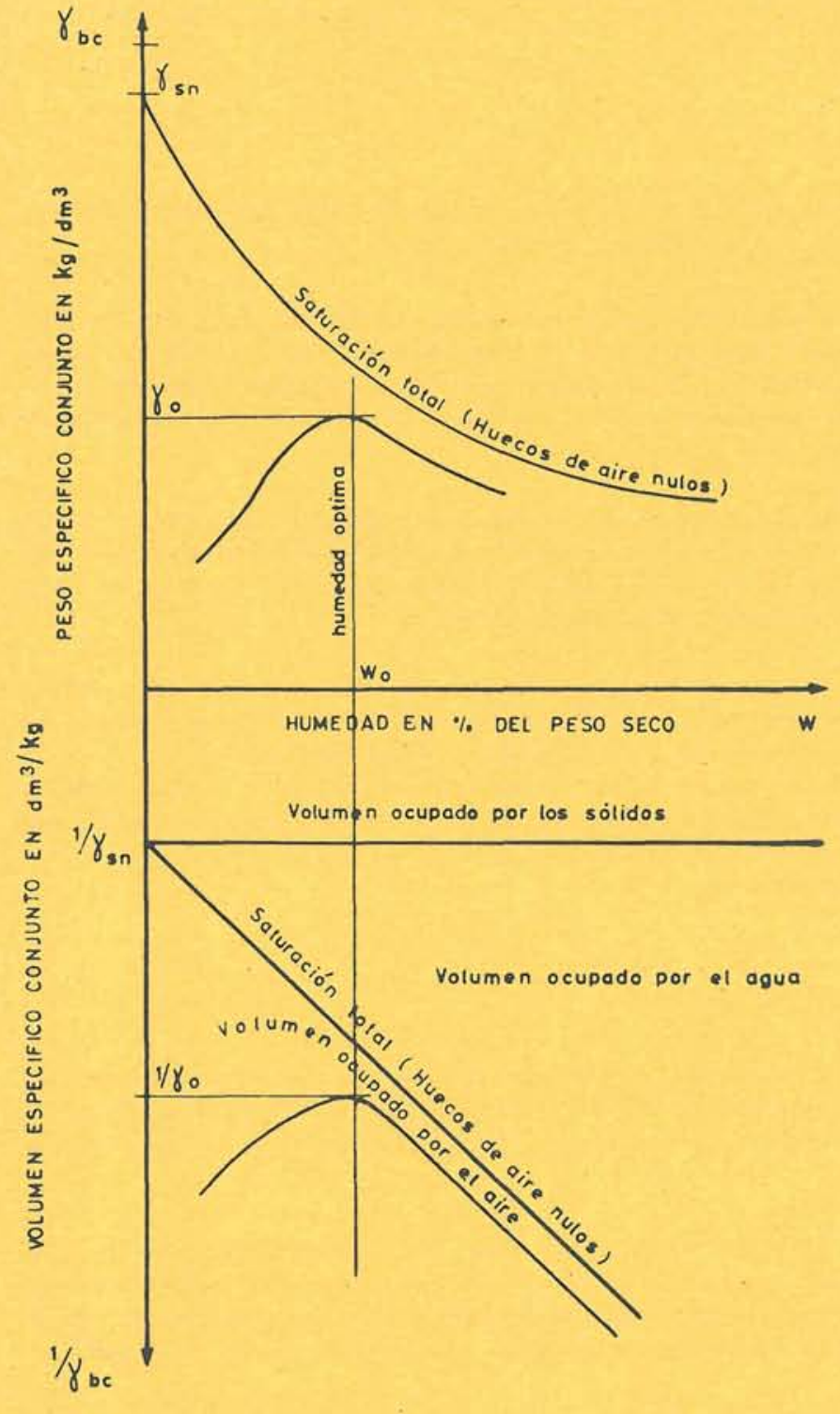

Fig. 9.-Ensayo normal de compactacíon.
Entonces se tiene:

$$
V_{s}=P_{s} / \gamma_{s n}
$$

y, por lo tanto:

$e=\frac{V_{n}}{V_{s}}=\frac{V_{t}-V_{s}}{V_{s}}=\frac{V_{t} \gamma_{s n}}{P_{t}}-1=\frac{\gamma_{s n}}{\gamma_{b c}}-1$

siendo $\gamma_{b c}=P_{s} / V$, el peso específico conjunto de la base (o sea, el de la base seca, con inclusión de los huecos que quedan entre sus partículas). De las fórmulas anteriores se deduce que, siendo fijo $\gamma_{s n}$, para disminuir el índice de huecos, $e$, basta aumentar el peso específico conjunto, $\gamma_{b c}$.

La compactación, cuyo objeto es disminuir los huecos ocupados por el aire (aumentando, por lo tanto, el peso específico conjunto, pero también el grado de saturación) se realiza aplicando a la base un trabajo mecánico. Es fácil ver que un trabajo por unidad de volumen tiene las mismas dimensiones que una presión, y, efectivamente, a la base se la comprime por medio de la compactación: así que al trabajo unitario de compactación se le denomina también «presión equivalente».

4.2.3. Papel del agua en la compactación.-La influencia del contenido de agua en el momento de compactar (humedad de compactación) es importantísima y se pone de manifiesto en el «ensayo normal de compactación». Si en unas condiciones operatorias determinadas se compactan muestras de base con una proporción fija de cemento, aplicando una misma presión equivalen-
te, $p_{1}$, el peso específico conjunto obtenido varía de la forma que se indica en la figura 9 , en la que te, $p_{1}$, el peso específico conjunto obtenido varía de la forma que se indica en la figura 9 , en la que
también se ha representado la variación de su inverso, el volumen específico conjunto (dado que muchos de los parámetros que se manejan son lineales en volúmenes). Se ve en dicha figura que, a medida que el contenido de humedad crece, el agua lubrica las partículas durante la compactación, facilitando su disposición según estructuras internas más cerradas y estables (menor índice de huecos y mayor peso específico conjunto y grado de saturación); este fenómeno se presenta hasta una humedad «óptima», $W_{o}$, a partir de la cual ya no se expulsa el aire: se ha alcanzado la pseudosaturación, el índice de huecos aumenta a costa de nuevos huecos totalmente rellenos de agua (y, por consiguiente, el peso específico conjunto baja), y las partículas se distancian unas de otras, flotando, por así decirlo, en el agua intersticial; por lo que los contactos entre ellas son menos intensos, y las estructuras internas más huecas e inestables: en estas condiciones la base se deforma fácilmente, produciéndose al compactar fenómenos de arrollamiento.

Como se ha visto, se puede alcanzar un mismo peso específico conjunto con dos humedades diferentes, una inferior y otra superior a la óptima. Sin embargo, las condiciones resistentes no son las 


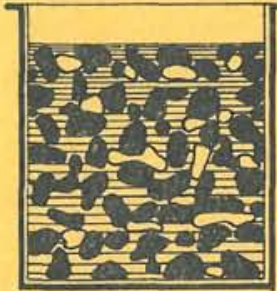

mismas. En el primer caso, la estructura interna se ha logrado por acercamiento de las partículas (por efecto de la compactación), y multiplicando los contactos entre ellas; mientras que en el segundo caso, las partículas se hallaban distanciadas precisamente por el exceso de agua, que, al desaparecer luego, las deja dispuestas según estructuras internas inestables (fig. 10).

Por lo tanto, si se quiere que la base presente propiedades resistentes, tanto durante la compactación (que faciliten su refino) como después de ella (durante su vida útil), no se debe compactar con humedades superiores a la óptima.

Ahora bien: complica las cosas el hecho de que la humedad óptima (y el peso específico máximo correspondiente a ella) son función de la presión equivalente, o sea, de la energía compactiva puesta en juego.

4.2.4. Influencia de la energía de compactación.-Si se repite el ensayo de compactación con una presión equivalente, $p_{2}$. mayor que $p_{1}$, se observa (figura 11) que la reducción del índice de huecos y, por lo tanto, el peso específico conjunto, es mayor, como era de esperar, puesto que la mayor energía compactiva es capaz de expulsar aún algo del aire que antes se quedaba absorbido. Pero al mismo tiempo la humedad óptima es menor: la pseudosaturación se alcanza antes.

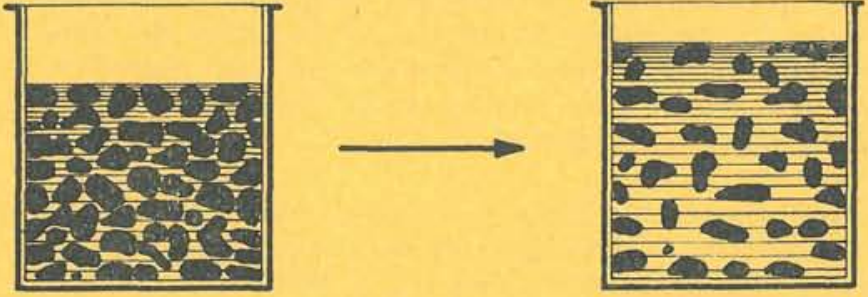

Fig. 10.-Estructura interna de la base.

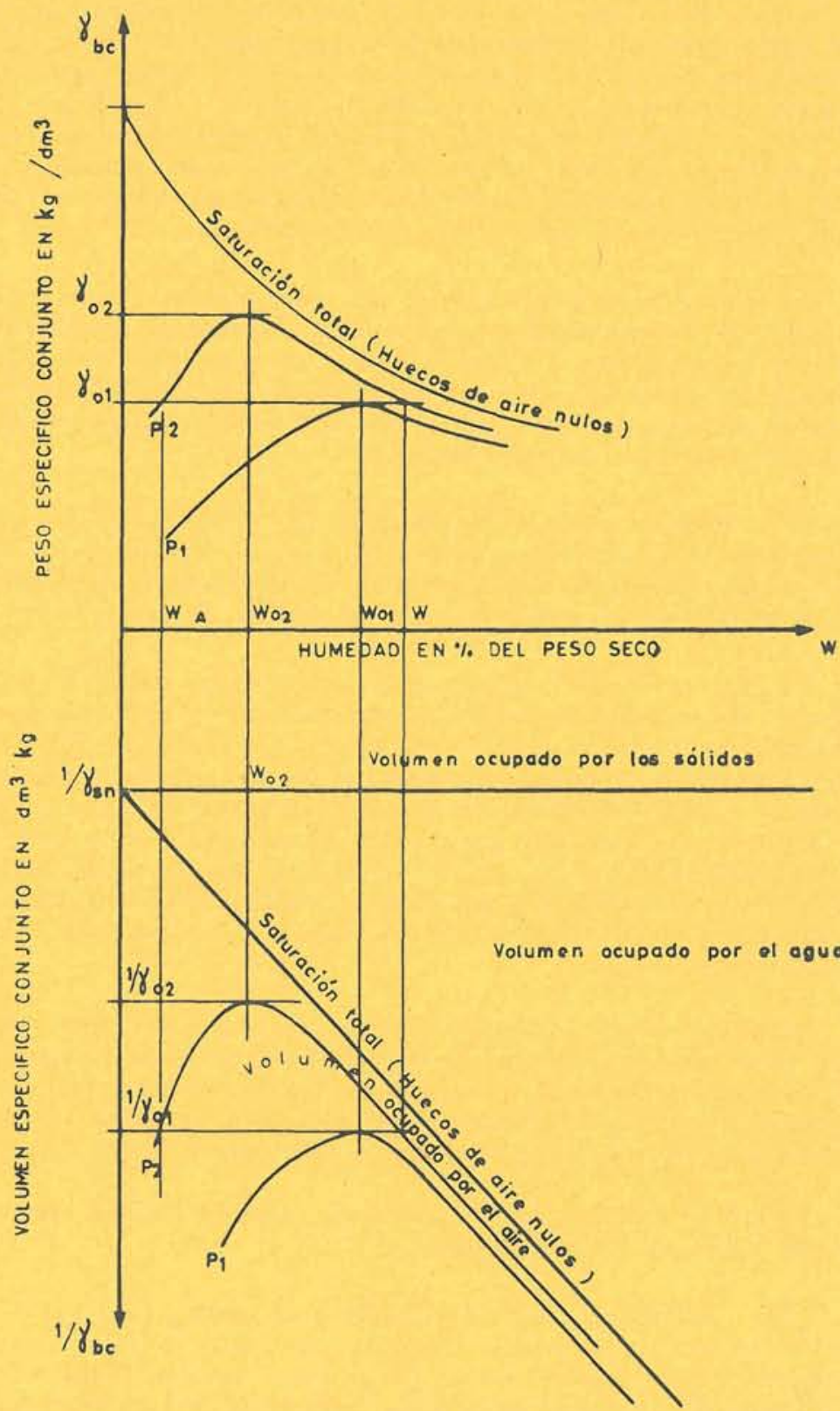

Fig. 11.-Influencia de la energía de compactación. 
En la práctica, la compactación se realiza con una humedad prácticamente constante ( $w$ fija), aumentando progresivamente la energía aplicada ( $p$ creciente) hasta alcanzar un peso específico conjunto que se estima como satisfactorio, porque lleva aneja una estructura interna suficientemente estable; la hidratación del cemento «congela» entonces, por así decirlo, esa estructura haciendo que sucesivas aportaciones de energía por la acción del tráfico, y en presencia de diversas humedades, no se traduzcan en aumentos ulteriores del peso específico conjunto, provocando asientos que podrían ser perjudiciales para el pavimento. Esta es una de las ventajas de las bases estabilizadas con cemento sobre los demás tipos de base.

Del examen de lä figura 11 resulta evidente que un mismo peso específico conjunto, $\gamma_{01}$, puede ser alcanzado de dos maneras diferentes: con la presión equivalente $p_{1} \mathrm{y}$, precisamente, la humedad óptima correspondiente a ella, $w_{01}$; o bien con la presión equivalente, $p_{2}$ (siempre mayor que $p_{1}$, puesto que $\gamma_{01}$ corresponde al óptimo), y con dos contenidos de humedad muy diferentes: $w_{\mathrm{A}}$, menor que el óptimo, $w_{02}$, correspondiente a $p_{2}$, y $w_{\mathrm{B}}$, superior a dicho óptimo e, incluso, a $w_{01}$. Las condiciones resistentes de la base para un peso específico conjunto, $\gamma_{01}$ (que se supone es el deseable) son distintas según haya sido la humedad de compactación: si ésta ha sido $w_{\mathrm{A}}$, habrá hecho falta aplicar una (menor que $p_{2}$ y, por lo tanto, más económica); y sihabrá bastado aplicar una presión equivalente, $p_{1}$ presión equivalente, $p_{2}$; si la humedad ha sido $w_{01}$, ha sido $w_{\mathrm{B}}$, habrá sido necesario aplicar una presión $p_{2}$, y además se habrá alcanzado la pseudosaturación, con consiguiente pérdida de cualidades resistentes. También hay que observar que, si con humedad $w_{01}$, se aplica una energía mayor que la $p_{1}$, correspondiente a cuando dicha humedad sea óptima, se obtiene un peso específico conjunto mayor, pero cayendo de nuevo en la pseudosaturación.

La presión equivalente que se fija como mínima es de $6,05 \mathrm{~kg} / \mathrm{cm}^{2}$, correspondiente al Ensayo Normal de Compactación. A ella corresponden unas «condiciones óptimas» (peso específico conjunto $\gamma_{0}$ y humedad $w_{0}$ ). En obra se exigirá un peso específico conjunto igual o superior a $\gamma_{01}$, el cual deberá ser alcanzado con una humedad no superior a la óptima correspondiente a la presión equivalente aplicada: cuando esta última sea de $6,05 \mathrm{~kg} / \mathrm{cm}^{2}$, dicha humedad será precisamente $w_{0}$; con presiones inferiores no se alcanzará $\gamma_{0}$.

4.2.5. Influencia de la dosificación de cemento.-En las consideraciones de los dos epígrafes anteriores, se ha supuesto que la dosificación de cemento era constante. Sin embargo, la realidad es que dicha dosificación tiene influencia en el resultado del Ensayo Normal de Compactación, el cual, como se ha visto, es el fundamento del estudio de dosificación.

La explicación de la variación en el resultado del E. N. C. por causa de la variación de la proporción de cemento es doble; por un lado, el cemento tiene una densidad mayor que el material natural con el que se mezcla, resultando, por tanto, que los «sólidos» tienen un peso específico neto creciente con la proporción de cemento. Por el contrario, al mezclarse los sólidos con agua al compactarse, se verifican ciertos fenómenos fisicoquímicos: la hidratación parcial del cemento, que disminuye la cantidad de agua libre para actuar de lubricante en la compactación; y una coagulación del cemento hidratado, que aumenta el rozamiento interno de los sólidos. Por estas razones ocurre generalmente que, a medida que aumenta la dosificación de cemento (y el tiempo que transcurre desde el amasado hasta la compactación), la humedad óptima sube y el peso específico conjunto a ella correspondiente baja.

La proporción de cemento es, por lo tanto, a la vez dato y solución del estudio de dosificación; o sea, para realizar el Ensayo Normal de Compactación (y seguir después con el estudio) hay que presuponer una dosificación de cemento, en función de las características identificatorias del material natural; y proceder por aproximaciones sucesivas, repitiendo, si es preciso, el estudio con una nueva. dosificación de cemento inicial más acorde con la final.

La tabla I indica las dosificaciones de cemento iniciales para realizar el ensayo de compactación. según el tipo de material natural.

4.2.6. Estima «a priori» del resultado del Ensayo Normal de Compactación.-En algunos casos de suelos arenosos, puede ser interesante, con cierta aproximación, conocer «a priori» el peso específico conjunto máximo que se va a obtener en el Ensayo Normal de Compactación, puesto que con este dato estimado se puede calcular la dosificación de cemento necesaria para dicho ensayo. (Véase más: adelante, 4.3.) 
T A B L A I

TIPO DE MATERIAL NATURAL.
Dosificación de cemento para el

ensayo normal de compactación, en $\%$ del peso de material natural

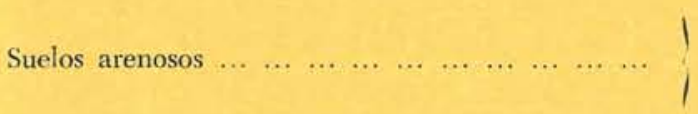

Suelos limoarcillosos: $\left\{\begin{array}{l}\text { Poco plásticos } \ldots \ldots \ldots \\ \text { Plásticos } \ldots \ldots \ldots \ldots\end{array}\right.$

A-1-a
A-1-b
A-2
A-3
A-4 y A-5
A-6
A-7

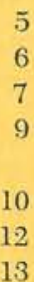

- Para suelos procedentes del horizonte «A», aumentar : $4 \%$ si el color es gris.

$6 \%$ si el color es negro.

Esta estima, basada en datos estadísticos, se refleja en la figura 12, y tan sólo es aplicable a suelos con una fracción máxima del 50 por 100 inferior a $0,05 \mathrm{~mm}$, y máxima del 20 por 100 inferior a $0,005 \mathrm{~mm}$; y que no contengan partículas retenidas en el tamiz \# 4 (4,76 mm), cuyo peso específico neto sea inferior a 2,45 .

4.2.7. Interpretación del resultado del Ensayo Normal de Compactación.-Por medio del Ensayo Normal de Compactación se han determinado un peso específico conjunto mínimo (que será luego el que se exija en obra) y una humedad óptima máxima para alcanzarlo. Parece a primera vista que dichos datos son solamente útiles para la obra; pero, sin embargo, el primero de ellos (peso específico conjunto) sirve también para caracterizar los suelos, de forma que constituye un dato identificatorio más, en función del cual es posible deducir la dosificación de cemento adecuada. En los áridos, dicho dato no es significativo para el proyecto.

Se consideran por separado los suelos arenosos y los suelos limoarcillosos. En los primeros, puede procederse de dos maneras, según se vayan a aplicar los ensayos de abrasión o los ensayos acelerados: ambas están fundadas en una correlación estadística entre la granulometría del suelo, el peso específico conjunto mínimo obtenido en el E. N. C., y la closificación de cemento adecuada; la tabla II expresa esta correlación para el caso de ensayos de abrasión, y la figura 13 la expresa en forma de ábaco para el caso de los ensayos acelerados (sólo aplicables a los suelos mencionados en 4.2.6).

Para los suelos limoarcillosos existe también una correlación estadística, en la que interviene además la plasticidad, en forma del parámetro conocido universalmente bajo el nombre de «índice de grupo»; se expone en la tabla III.

\subsection{Dosificación mínima de cemento.}

El Ensayo Normal de Compactación ha facilitado los siguientes datos para proseguir el estudio de dosificación:

- Peso específico conjunto máximo que debe alcanzar la base.

- Humedad óptima correspondiente a una presión equivalente de $6,05 \mathrm{~kg} / \mathrm{cm}^{2}$, con la que se a!canza el peso específico anterior.

- Dosificación de cemento media para los ensayos subsiguientes: 5 por 100 para los áridos, y una función de las características identificatorias y del peso específico alcanzado para los suclos (véase 4.2.7). 


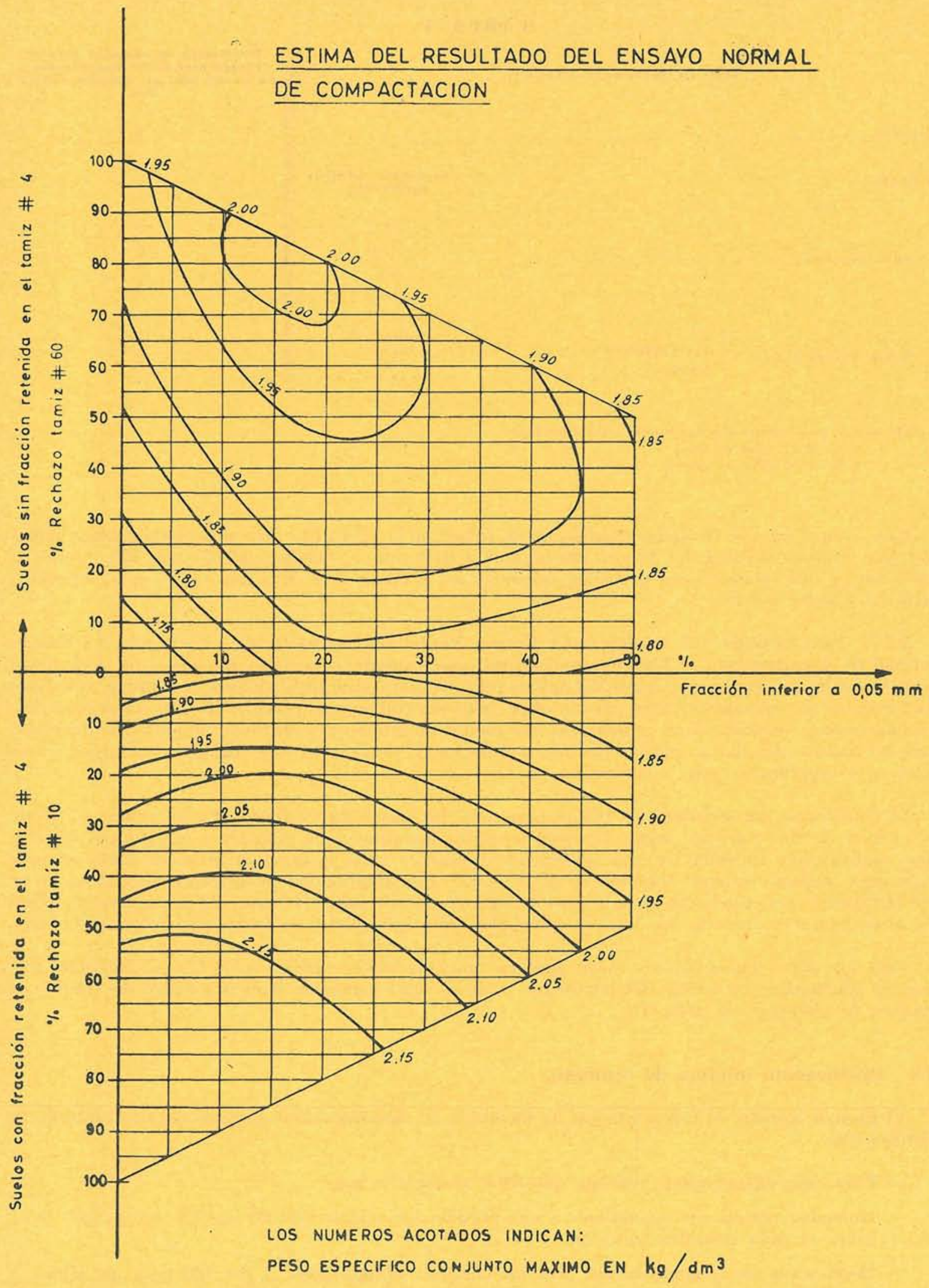

Fif. 12. 
TA B L A I I

Dosificación media de cemento (\% del peso de suelo seco) Para suelos arenosos procedentes del horizonte B o C

PESO ESPECIFICO CONJUNTO MAXIMO ALCANZADO EN EL E. N. C.

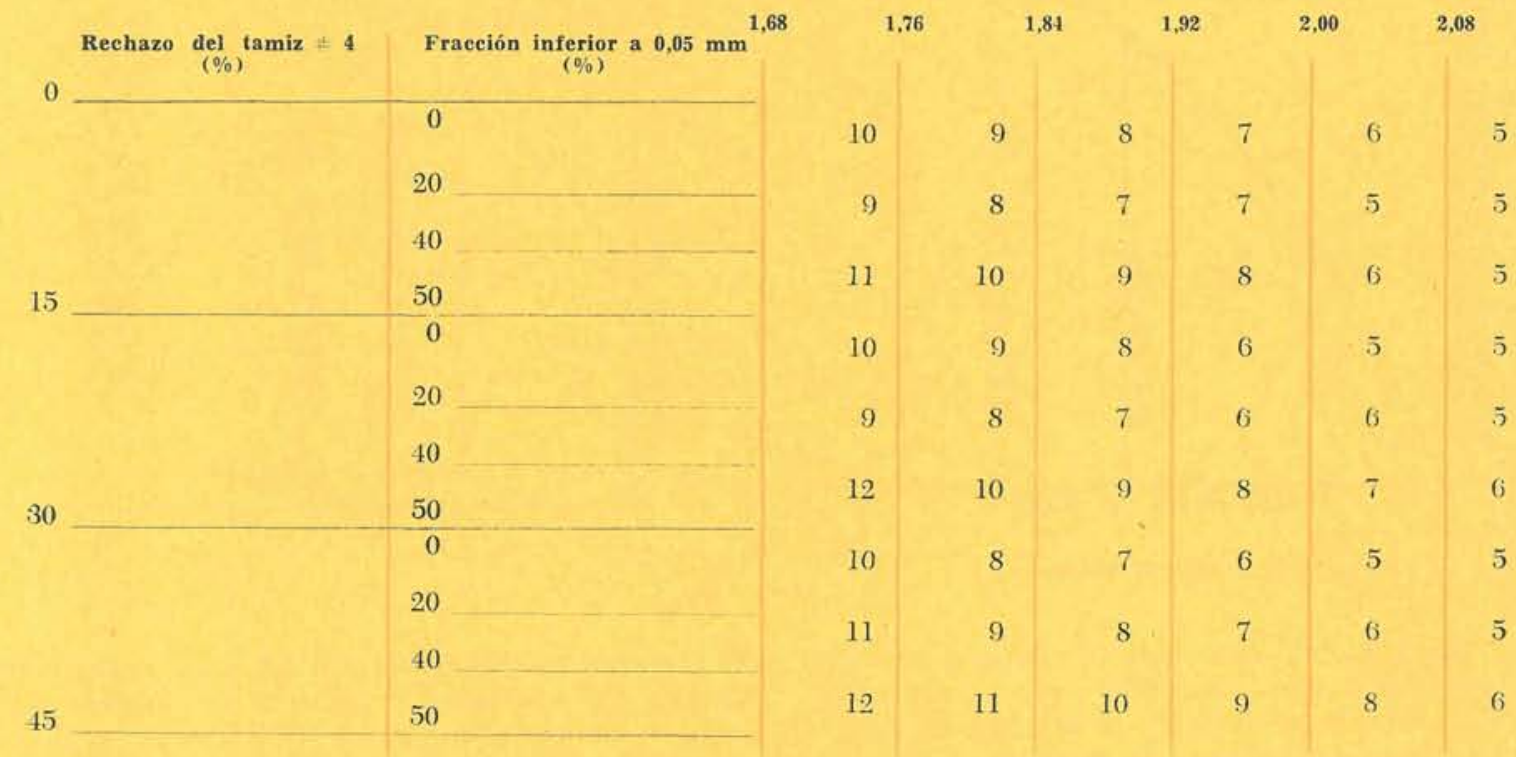

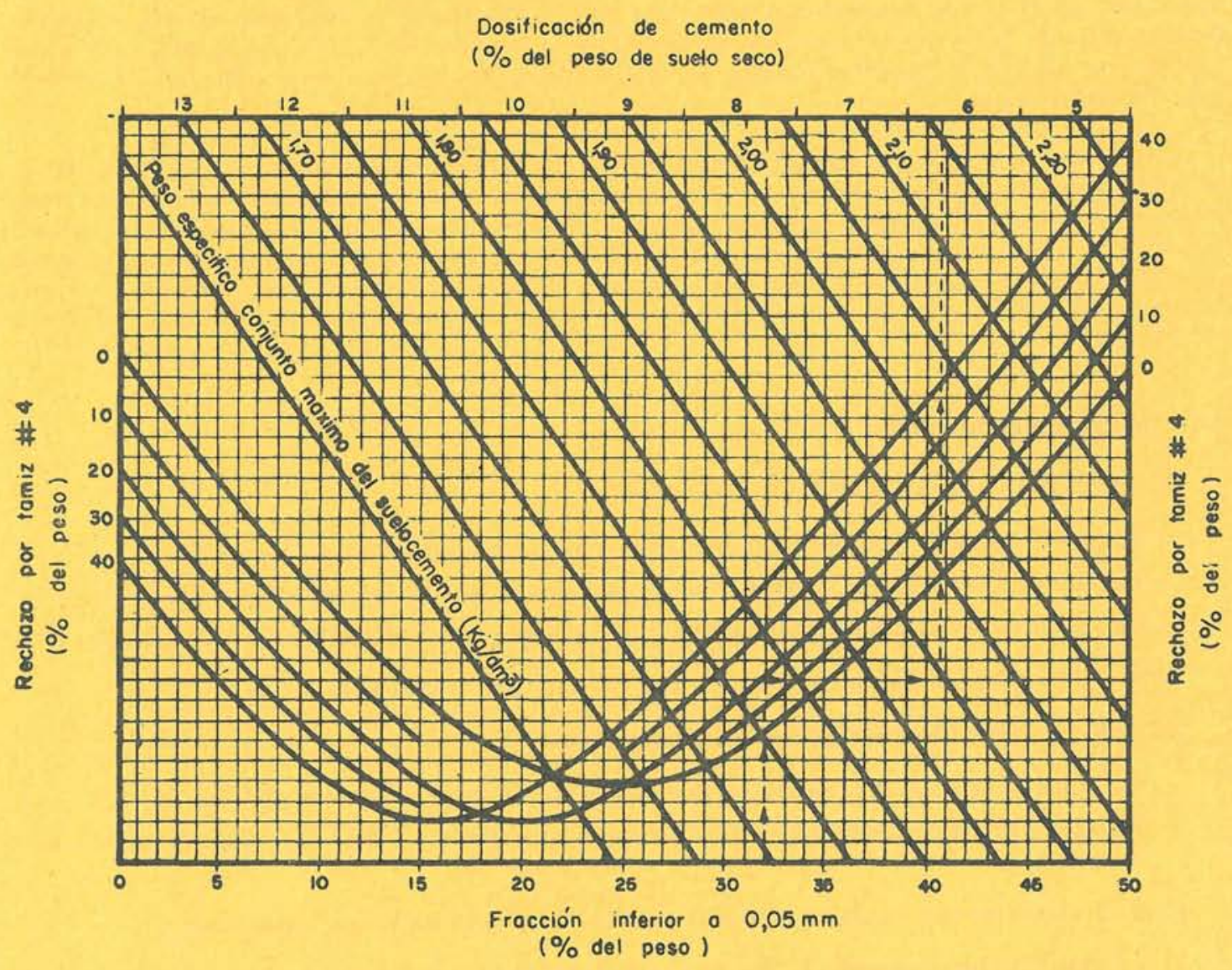

Fig. 13.-Dosificación media de cemento para suelos arenosos. 
CONDICION CRITICA

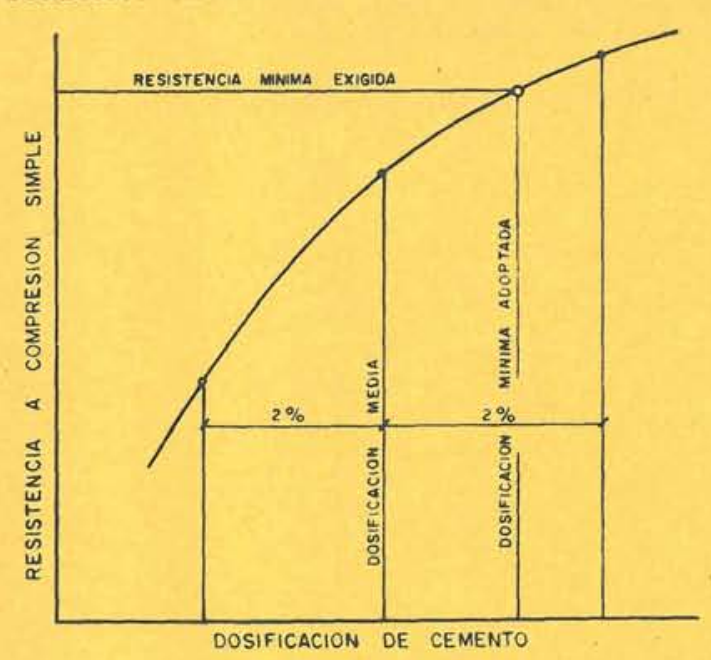

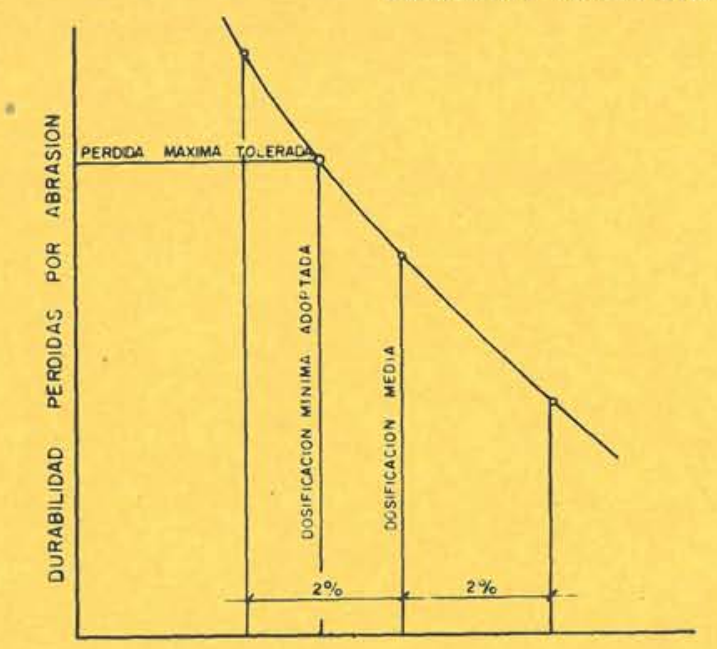

Fig. 14,-Ejemplos de estudio de dosificación.

Elegida entonces una condición facultativa crítica entre las enumeradas en 2.3 ó 2.4 (entendiendo por crítica una condición cuyo cumplimiento requiere una dosificación tal, que se cumplen automáticamente las demás), se realizan los ensayos correspondientes sobre series de probetas moldeadas con tres dosificaciones de cemento: la media antes mencionada; la media menos 2 por 100 , y la media más 2 por 100. Con los resultados se traza una gráfica en la que se interpola el valor mínimo de la dosificación que hace que se cumplan las condiciones exigidas en 2.3 ó 2.4 (fig. 14). Para todas estas probetas se adopta la humedad óptima de compactación del E. N. C. y el peso específico conjunto a ella correspondiente.

Existe una excepción al método de interpolación anteriormente expuesto: los criterios de ensayos acelerados de durabilidad para sueios arenosos, expuestos en 2.4.4.2 (fig. 2), indican una resistencia mínima a compresión simple a los siete días, que debe ser alcanzada con la dosificación deducida del ábaco de la figura 13; en caso contrario, deben realizarse los ensayos normales de durabilidad (pérdidas por abrasión). Algunas veces se ha recurrido, en cambio, a dividir la dosificación que arroja una resistencia deficiente, por la razón entre ésta y la exigida, adoptando, como definitiva, la dosificación modificada.

\subsection{Utilización en obra.}

De los estudios anteriores hemos deducido:

- El peso específico conjunto mínimo que debe presentar la base: $\gamma_{0}\left(\mathrm{~kg} / \mathrm{dm}^{3}\right)$.

- La humedad óptima en el momento de compactar: $w_{0}(\%$ del peso seco de la base).

- La dosificación mínima de cemento: $c$ (\% del peso seco del material natural).

En los planos está definido el espesor $e(\mathrm{~cm})$ de la base terminada.

En obra se debe disponer de los siguientes datos:

- La humedad inicial del material natural, $w_{i}$ (\% del peso seco de dicho materiai).

- El peso específico conjunto inicial del material natural, $\gamma_{i}\left(\mathrm{~kg} / \mathrm{dm}^{3}\right)$ (en el caso de mezcla en capa).

Para la obra interesa conocer, a partir de los datos anteriores, los siguientes:

- La cantidad de cemento, $C\left(\mathrm{~kg} / \mathrm{m}^{2}\right)$, necesaria por unidad de superficie.

- La cantidad de agua, 'W $\left(1 / \mathrm{m}^{2}\right)$ que hay que añadir, también por unidad de superficie. 


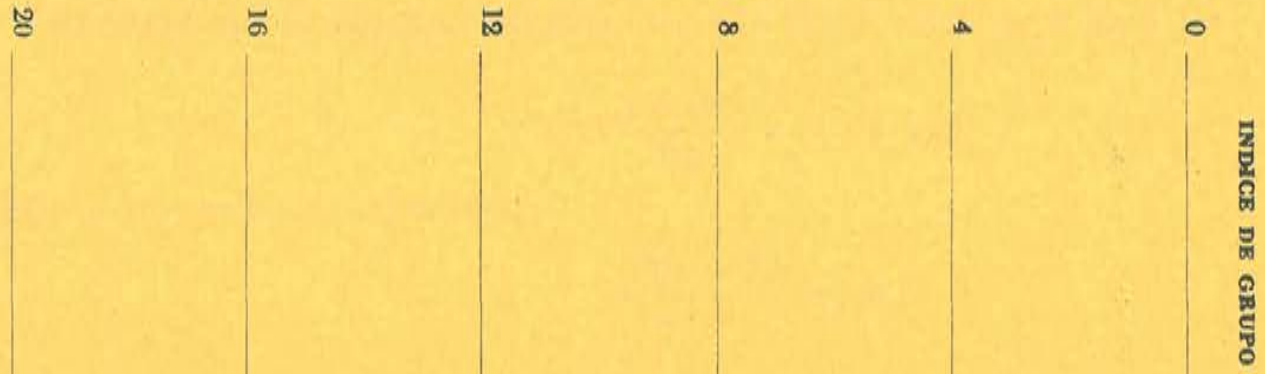

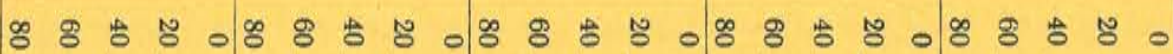

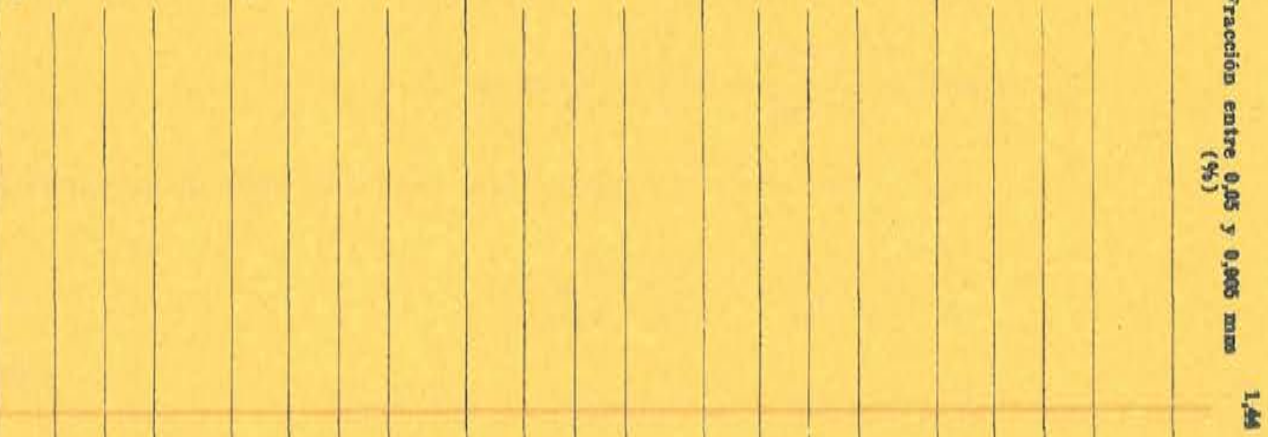

8

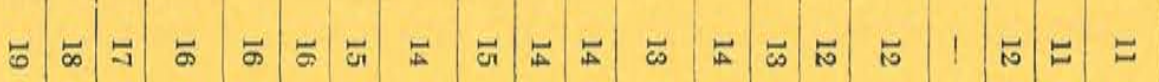

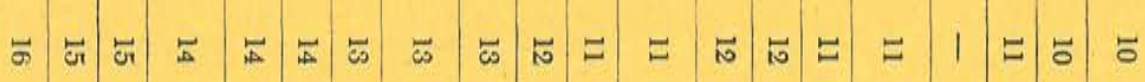

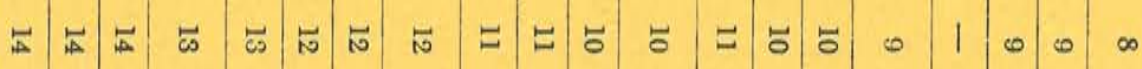

点

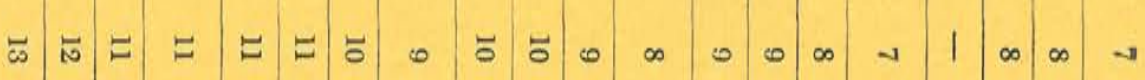

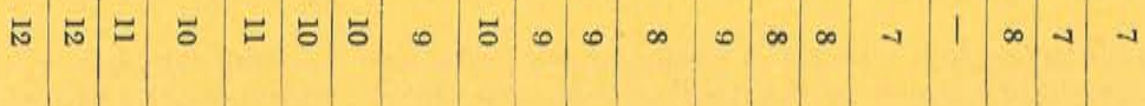


- El espesor inicial, $e_{i}(\mathrm{~cm})$, que hay que mezclar (en el caso de mezcla en capa) para que una vez humedecido y compactado se obtengan el espesor y densidad requeridos.

Entre todos los parámetros anteriores, existen relaciones sencillas que se deducen a continuación.

En un metro cuadrado de base terminada hay un volumen de base:

$$
\frac{e}{100}\left(\mathrm{~m}^{3}\right)
$$

Como este volumen presenta un peso específico $\gamma_{0}\left(\mathrm{~kg} / \mathrm{dm}^{3}\right)$, el peso de la base será:

$$
10 \cdot e \cdot \gamma_{0}\left(\mathrm{~kg} / \mathrm{m}^{2}\right) \text {. }
$$

En este peso entran el material natural y el cemento, siendo el peso de este último un $c \%$ del peso del primero. Por lo tanto, el peso de material natural será:

$$
\frac{1000 \cdot e \cdot \gamma_{0}}{100+c}\left(\mathrm{~kg} / \mathrm{m}^{2}\right)
$$

y, por lo tanto, el peso del cemento será:

$$
C=\frac{10 \cdot e \cdot c \cdot \gamma_{0}}{100+c}\left(\mathrm{~kg} / \mathrm{m}^{2}\right)
$$

En la práctica, $C$ oscila entre 1,0 y $2,4 \mathrm{~kg} / \mathrm{m}^{2}$ por centímetro de espesor de base. En cuanto al agua, la cantidad total necesaria será:

$$
\frac{w_{0} \cdot e \cdot \gamma_{0}}{10}\left(1 / \mathrm{m}^{2}\right)
$$

Pero teniendo en cuenta que inicialmente, en el material natural, había presente una cantidad de agua

$$
\frac{1000 \cdot e \cdot \gamma_{0}}{100+c} \cdot \frac{w_{i}}{100}\left(1 / \mathrm{m}^{2}\right)
$$

la cantidad de agua que haya que añadir a la base será:

$$
W=\frac{e \cdot \gamma_{0}}{10}\left(w_{0}-\frac{100 \cdot w_{i}}{100+c}\right)\left(1 / \mathrm{m}^{2}\right)
$$

En la práctica, esta cantidad oscila entre 0 y $2 \mathrm{l} / \mathrm{m}^{2}$ por centímetro de espesor de base.

En cuanto al espesor, $e_{i}$, inicial necesario para obtener la cantidad de material natural que se precisa, se deduce teniendo en cuenta que el volumen inicial del mismo será:

$$
\frac{e \cdot \gamma_{0}}{(100+c) \gamma_{t}}\left(\mathrm{~m}^{3} / \mathrm{m}^{2}\right)
$$

para lo cual hace falta un espesor:

$$
e_{1}=\frac{100}{100+c} \cdot \frac{\gamma_{0}}{\gamma_{i}} \cdot e(\mathrm{~cm}) .
$$

En la práctica, el coeficiente multiplicativo de $e$ puede variar entre 0,9 y 1,4 . 


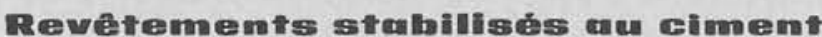

Sandro Rocei, ingénieur des Ponts et Chaussées.

Dans le premier d'une série d'articles qui comprendront tous les aspects, théoriques et pratiques, de l'emploi du ciment pour la stabilisation des sols en revêtements routiers, l'auteur fait un exposé des caractéristiques des matériaux employés et du produit terminé et établit des critères d'aptitude et de dosage les plus usuels.

\section{Eement stabilized bussess}

Sandro Rocei, civil engineer.

In this first article, out of a series of them, dealing with the theoretical and practical aspects of the stabilisation of pavements with cement, the author examines the properties of the various materials involved, and of the final pavement, and he enunciates what are the most usual standards of efficiency and proportioning.

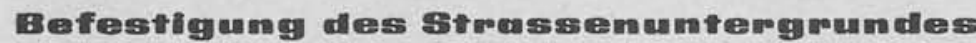 mait Zement}

Sandro Rocei, Strassenbauingenieur.

In dem ersten einer Reihe von Artikeln, die die theoretischen und praktischen Aspekte der Untergrundbefestigung im Strassenbau mit Zement zum Gegenstand haben, prüft der Verfasser die Eigenschaften der verwendeten Materialien und des fertigen Produktes und stellt eine Reihe von Kriterien über Eignung und Dosierung aup. 